\title{
A Comparative Study: Fast and Direct Voltammetric Measurements of Adenosine and Uric Acid at Copper and Carbon Fiber as Sensors
}

\author{
K. M. Abou El-Nour ${ }^{1,2, *}$, G. A. M. Mersal ${ }^{3}$ \\ ${ }^{1}$ Department of Chemistry, University of Florida, Gainesville, Florida, 32611-7200, USA. \\ ${ }^{2}$ Permanent address: Department of Chemistry, Suez Canal University, Ismailia 41522, Egypt. \\ ${ }^{3}$ Department of Chemistry, College of Science, Taif University, P.O. Box 11099, Taif 21944, Saudi \\ Arabia. \\ *E-mail: kabolnoor@yahoo.com, khloud_abouelnour@science.suez.edu.eg, gamersal@tu.edu.sa, \\ gamersal@yahoo.com
}

Received: 28 January 2021 / Accepted: 17 June 2021 / Published: 10 August 2021

\begin{abstract}
Sensitivity of copper sensor (CS) has been tested for the first time using fast scan in direct voltammetric detection of uric acid (UA) and adenosine (ADO). Copper sensor was activated in basic medium, where the stability of the sensor can be achieved as a result of the dissolution of surface layers. Sensitivity of CS (20 $\mu \mathrm{m}$ diameter) was compared to the sensitivity of carbon fiber sensor (CFS) ( $7 \mu \mathrm{m}$ diameter) for the determinations of UA and ADO after activation of the sensor surface in $70 \mathrm{mmol} \mathrm{L}^{-1}$ phosphate buffer $\mathrm{pH}$ 7.4. Good stability and reproducibility of the background current at copper sensor, which was exploited in on-line background subtraction, was observed following electrochemical activation/treatment in the potential window from -0.5 to $+0.85 \mathrm{~V}$. The stability and reproducibility were strongly dependent on the potential window used for treatment and detection. UA sensitivity was

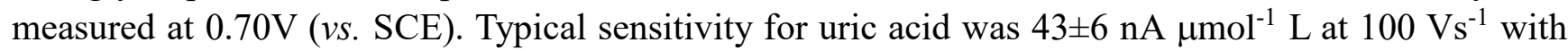
100 cycles at copper sensor. More stable responses were observed in a potential range from +0.6 to $0.0 \mathrm{~V}$ (vs. SCE), but with less sensitivities. At CFS, the measured UA sensitivity was $0.043 \pm 0.002 \mathrm{nA} \mathrm{mol}^{-1}$ $\mathrm{L}$ at $0.3 \mathrm{~V}$ ( $v s$. SCE). Adenosine sensitivity at CS was found to be $0.028 \pm 0.003 \mathrm{nA}^{\mathrm{m}} \mathrm{mol}^{-1} \mathrm{~L}$ at $0.5 \mathrm{~V}$ ( $v s$. SCE) at $100 \mathrm{~V} \mathrm{~s}^{-1}$ with 100 averaging cycles, while at CFS, the measured ADO sensitivity was $0.150 \pm 0.002$ at $1.4 \mathrm{~V}$ (vs. SCE).
\end{abstract}

Keywords: Copper sensors, Carbon fiber sensors, Fast scan voltammetry, adenosine, Uric acid.

\section{FULL TEXT}

(C) 2021 The Authors. Published by ESG (www.electrochemsci.org). This article is an open access article distributed under the terms and conditions of the Creative Commons Attribution license (http://creativecommons.org/licenses/by/4.0/). 